\title{
Lettre de la rédaction
}

Philippe Erikson

\section{(2) OpenEdition}

Journals

Édition électronique

URL : https://journals.openedition.org/jsa/17832

DOI : 10.4000/jsa.17832

ISSN : 1957-7842

\section{Éditeur}

Société des américanistes

\section{Édition imprimée}

Date de publication : 30 juin 2020

Pagination : 7-8

ISBN : 978-2-902715-13-8

ISSN : 0037-9174

\section{Référence électronique}

Philippe Erikson, «Lettre de la rédaction», Journal de la Société des américanistes [En ligne], 106-1 | 2020, mis en ligne le 30 juin 2020, consulté le 26 septembre 2022. URL : http://

journals.openedition.org/jsa/17832 ; DOI : https://doi.org/10.4000/jsa.17832 


\section{Lettre de la rédaction}

Ordinairement, la couverture du JSA reprend l'iconographie d'un des articles au sommaire. Si le présent numéro déroge à cette coutume, c'est que sa sortie coïncide avec une période qui sort dramatiquement de l'ordinaire. La rédaction a donc choisi ce graffiti photographié au Brésil, qui met à l'honneur un peuple emblématique (les Yanomami), une couleur qui ne l'est pas moins (le rose) ${ }^{1}$ et, surtout, un concept dont le besoin se fait aujourd'hui cruellement sentir: celui de respect.

Du nord au sud du continent, en ces temps de coronavirus, les populations amérindiennes subissent la pandémie de plein fouet. Beaucoup ont été affectées de façon disproportionnée, laissées à l'abandon, victimes de taux de létalité bien supérieurs à ceux du reste de la population. Ces situations désastreuses sont évidemment corrélées au manque chronique de ressources et à des états de santé déjà fragiles. Mais elles résultent tout aussi incontestablement de l'irrespect, du mépris, voire de la haine trop souvent affichés à leur égard par les autorités publiques de leurs pays respectifs.

La communauté scientifique n'a pas non plus été épargnée par le Covid-19. Elle aussi compte ses morts, comme en attestent les hommages publiés dans notre rubrique nécrologique pour honorer la mémoire de ces éminents américanistes emportés par le coronavirus: Gérald Taylor (01/04/2020), Sylvie Vincent (30/04/2020), Robert Laughlin (28/05/2020).

Sur un registre moins tragique, mais non moins préoccupant, notre appel au respect s'adresse aussi à nos instances de tutelle. À l'unanimité moins une voix, notre comité de rédaction a en effet décidé de se solidariser avec le mouvement « Revues en lutte », qui réunit à ce jour 156 revues scientifiques de sciences humaines et sociales, en publiant l'éditorial commun qui ouvre ce

1. Pour rendre l'allusion moins cryptique, précisons que la couleur rose du graffiti reproduit sur la couverture a tout l'air d'un clin d'œil à la lutte contre l'homophobie et les discriminations sexuelles. 
numéro. Son contenu exprime notre inquiétude - partagée par la quasi-totalité de la communauté scientifique hexagonale - de voir fragilisé, par des réformes annoncées et en cours, un service public de l'enseignement supérieur et de la recherche dont les revues scientifiques constituent un rouage essentiel.

Sans doute serait-il vain d'essayer de traduire le terme respeito dans une langue amérindienne, du moins sans recours à l'emprunt ou à des paraphrases aussi élaborées que celles qui seraient nécessaires pour rendre le concept yanomami de waitheri dans une langue d'origine européenne ${ }^{2}$. Dans l'urgence, on se contentera donc des quatre langues traditionnelles du JSA pour réclamer: respeito, respect, respeto, respect...

Philippe ERIKSON

2. Le terme waitheri a été initialement popularisé par la très sulfureuse œuvre de Napoleon Chagnon, qui proposait de le traduire par « féroce » ou « agressif », conformément au portrait belliciste qu'il brossait de ce peuple. Des études subséquentes et plus subtiles ont cependant fait émerger des valences moins brutales de ce terme qui - entre autres qualités éminemment respectables - renvoie aussi au courage, à l'audace, à la superbe et à certaines formes de générosité et d'altruisme. Pour une définition plus précise de ce lexème « sémantiquement complexe et sans équivalente en langue espagnole », on peut se référer à Marie-Claude Mattei Müller et Jacinto Serowë, Lengua y cultura Yanomami: diccionario ilustrado YanomamiEspañol, Español-Yanomami, Epsilon Libros, Caracas, 2007, p. 349. 